\title{
The empowerment of all modalities against cancer
}

Han S, Toh HC

Singapore Med J 2018; 58(11): 560-561; https://doi.org/10.11622/smedj.2018133

The page numbers for References 1, 2, 3, 5, 6 and 8 are incorrect in the printed journal. The online version of the article reflects the corrected references as follows:

1. Karabekiroğlu A, Demir EY, Aker S, Kocamanoğlu B, Karabulut GS. Predictors of depression and anxiety among caregivers of hospitalised advanced cancer patients. Singapore Med J 2018; 59:572-7.

2. Chng CL, Tan HC, Too CW, et al. Diagnostic performance of ATA, BTA and TIRADS sonographic patterns in the predication of malignancy in histologically proven thyroid nodules. Singapore Med J 2018; 59:578-83.

3. Wong RX, Low HYT, Tan DYH. Local experience with radiosurgery for vestibular schwannomas and recommendations for management. Singapore Med J 2018; 59:590-6.

5. Sheng MX, Wan LL, Liu CM, Liu CX. Is cryosurgery a feasible local therapy for bone metastatic prostate cancer? Singapore Med J 2018; 59:584-9.

6. Bsirini C, Smoller BR. Histologic mimics of malignant melanoma. Singapore Med J 2018; 59:602-7.

8. Yeo CP, Ng WY. Automation and productivity in the clinical laboratory: experience of a tertiary healthcare facility. Singapore Med J 2018; 59:597-601.

https://doi.org/10.11622/smedj.2018148 